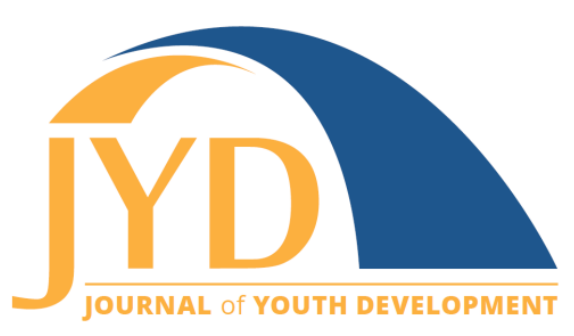

http://jyd.pitt.edu/ | Vol. 16 Issue 2-3 DOI 10.5195/jyd.2021.1037 | ISSN 2325-4017 (online)

\title{
Integrating Positive Youth Development: Insights From International Youth Development Programming
}

John E. Lindsay

International Youth Foundation (IYF)

j.lindsay@iyfnet.org

Shannon McGarry

International Youth Foundation (IYF)

s.mcgarry@iyfnet.org

Assem Satmukhambetova

International Youth Foundation (IYF)

a.satmukhambetova@iyfnet.org

Katie Raymond

International Youth Foundation (IYF)

k.raymond@iyfnet.org

\section{Arafat Lesheve}

International Youth Foundation (IYF)

a.lesheve@iyfnet.org

\section{Sarah Jonson}

International Youth Foundation (IYF)

s.jonson@iyfnet.org

\section{Hafez Neeno}

International Youth Foundation (IYF)

h.neeno@iyfnet.org.

\section{Cheradee Williams}

Step Forward NLA

cheradeewilliams@yahoo.com

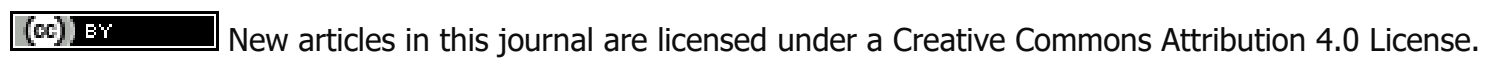
This journal is published by the University Library System, University of Pittsburgh and is cosponsored by the University of Pittsburgh Press. The Journal of Youth Development is the official peer-reviewed publication of the National Association of Extension 4-H Youth Development Professionals and the National AfterSchool Association. 


\begin{abstract}
Effective international youth development programs go beyond single-issue interventions-they leverage the entire organization and project life cycle to advance positive youth outcomes. This paper illustrates how positive youth development (PYD) approaches can be adapted for and applied by organizations to promote positive outcomes for young people and communities globally. The article provides 6 insights from the International Youth Foundation's (IYF) application of PYD principles across diverse youth development programs. Moreover, the authors present practical insights into what is required by practitioners, regardless of geographic boundaries, to effectively engage with, support, and meet the needs of youth and young adults whom they serve. Finally, the article argues that practitioners and funders need to find new ways to measure and value PYD investments and that funders need to make PYD integral across their funding streams.
\end{abstract}

Key words: youth engagement, cross-sectoral outcomes, positive youth development (PYD), systemsbased approaches, capacity building

\title{
Introduction
}

Youth development practitioners, community leaders, and researchers alike recognize that an asset-based approach to youth development programming improves outcomes for youth ${ }^{1}$ and their communities (Sanders et al., 2015; Ward et al., n.d.). Originating in the United States, positive youth development (PYD) has been adopted by the international development community over the past decade as programs have built a body of implementation-based evidence demonstrating the cross-sectoral benefits of integrating the asset-based principles of PYD in international programming (Alvarado et al., 2017).

Despite this growing evidence and the existence of practitioner-friendly frameworks such as USAID's PYD Framework² (YouthPower2, n.d.), the practical question of how to move beyond theoretical frameworks to fully integrate PYD principles into program activities and approaches continues to be a challenge. In short, how to best apply positive youth development within the real-world constraints of youth development programming has not yet caught up with the theoretical underpinnings.

\footnotetext{
${ }^{1}$ The IYF generally defines "youth" as being between the ages of 15 and 29 years. However, there is no standard definition and not all countries use the same definition for youth. Where national or local law differs, IYF follows the established local definition for youth in our programming.

${ }^{2}$ This framework illustrates that to achieve the vision of healthy, productive and engaged youth, PYD programs, practices, and policies must work with youth to improve their assets, agency, contribution, and enabling environment (YouthPower2, n.d.).
} 


\section{Integrating Positive Youth Development}

This paper examines these issues by sharing six insights from the International Youth Foundation's (IYF) application of PYD principles across diverse international youth development programs. In our experience, the programs most successful at advancing positive youth outcomes are those that go beyond single-issue interventions to integrate PYD into the entire organization and project life cycle.

We begin with the evolution of PYD in the U.S. and international contexts. Next, we illustrate how PYD approaches can be adapted for and applied by organizations in their programs to maximize impact. Finally, we provide insights about how one international development organization, IYF, has leveraged PYD principles in our work. We highlight specific programming examples that include practical insights into what is required by practitioners to effectively engage with, support, and meet the needs of young people whom they serve.

\section{Evolution of PYD}

Positive Youth Development (PYD) is an asset-based approach used by many international youth development practitioners to support young people's skill development, nurture their interests and values, incorporate youth voices and ideas, and connect them to supportive adults and resources (Sanders et al., 2015).

PYD has its roots in the U.S. health field. In the 1970 s and 80 s, prevention efforts typically focused on single-issue programs such as teen pregnancy, substance abuse, and juvenile delinquency. Through decades of youth work, practitioners, policymakers, funders, and researchers determined that an asset-based approach was a critical success factor and the focus shifted from prevention to the role of resiliency-including protective factors such as caring, supportive relationships; high expectations; and meaningful participation (Lee et al., 2012). By the late 90s, a broader conception of youth development emerged that focused on the whole child, their assets and needs, and their environment-rather than their deficiencies (Burkhard et al., 2020).

Today, PYD is considered a cornerstone of cross-sector youth development programs in the United States and is increasingly being used by international development practitioners. Building on the research and evidence base and informed by work in the United States, the U.S. Agency for International Development (USAID) has become a government leader in taking PYD abroad and applying the principles in diverse international contexts. Through their YouthPower 


\section{Integrating Positive Youth Development}

Learning program, USAID has supported the development of the USAID Positive Youth Development Framework, one of the frameworks that have provided a basis for the use of PYD across multiple sectors in low- and middle-Income countries (LMICs).

\section{Applying PYD to Program Implementation}

Around the world, international development organizations, practitioners, and policymakers are strengthening the work they do based on PYD and integrating asset-based approaches into their programs.

For 30 years, the International Youth Foundation (IYF) has championed PYD both as a guiding philosophy and a strategic part of our programming and operations. IYF began this journey in 1990, advocating for a "holistic approach" to support young people. From incorporating youth engagement, to co-creating platforms to elevate youth voice, to developing tools and approaches to strengthen youth agency, for over thirty years IYF has used an asset-based approach to demonstrate what is required to implement and advance youth programming, highlighting where PYD provides the necessary catalyst for effective change.

Frameworks are critical to help organizations and practitioners digest, understand, and integrate best practices into their work. They aid in staff direction, provide useful tools to orient and onboard partners, and help target approaches and interventions. While IYF has used assetbased and similar frameworks for several decades now, many international development organizations have only recently begun to do so. USAID's PYD framework presents a clear, holistic framing that is practitioner-friendly and relevant. Given its focus on low- and middleincome countries and contexts, USAID's framework is a particularly relevant starting point in helping international development organizations to embrace PYD principles and integrate PYDdriven practices into their projects.

Moving from theory to practice, it is important to recognize that there is no one right way to integrate PYD into programs; however, experience has shown that there are key questions that practitioners should ask-and answer-when doing so. IYF has developed a series of questions, (detailed in Table1), that align with USAID's PYD Framework and guide program teams when working to apply PYD in their programs. 
Table 1. Key Questions for PYD Implementation - Translating Theory to Practice

\begin{tabular}{|c|c|c|}
\hline $\begin{array}{l}\text { PYD } \\
\text { domain }\end{array}$ & $\begin{array}{l}\text { PYD } \\
\text { program feature }\end{array}$ & $\begin{array}{c}\text { Key questions for PYD implementation- } \\
\text { translating theory to practice }\end{array}$ \\
\hline 1. Assets & \multirow[t]{2}{*}{ Skill building } & \multirow{2}{*}{$\begin{array}{l}\text { How will the program build young people's skills? What are the different } \\
\text { types of skills necessary for success? How will staff and/or trainer practices } \\
\text { allow young people to develop those skills? What is the institutional context } \\
\text { for skill development? Where and how will the skills be applied? }\end{array}$} \\
\hline 2. Agency & & \\
\hline 3. Contribution & $\begin{array}{l}\text { Youth engagement } \\
\text { and contribution }\end{array}$ & $\begin{array}{l}\text { How are young people being encouraged to express themselves within the } \\
\text { program? How do adults learn how to share power and create mechanisms } \\
\text { for young people to authentically share in decision-making processes? Are } \\
\text { there capacity-strengthening activities directed towards adults to equip them } \\
\text { with these skills? How does the program integrate multiple youth } \\
\text { perspectives, including different identity groups? }\end{array}$ \\
\hline \multirow[t]{5}{*}{$\begin{array}{l}\text { 4. Enabling } \\
\text { environment }\end{array}$} & $\begin{array}{l}\text { Healthy relationships } \\
\text { and bonding }\end{array}$ & $\begin{array}{l}\text { How does the program intentionally foster supportive youth-adult } \\
\text { relationships and/or expand young people's access to positive role models? } \\
\text { How will the program facilitate positive peer relationships? }\end{array}$ \\
\hline & $\begin{array}{l}\text { Belonging and } \\
\text { membership }\end{array}$ & $\begin{array}{l}\text { How will the program recruit diverse participants? How will the program } \\
\text { intentionally create inclusive environments? How will staff and trainers be } \\
\text { equipped on how to address diversity, equity \& inclusion? }\end{array}$ \\
\hline & $\begin{array}{l}\text { Positive norms, } \\
\text { expectations, and } \\
\text { perceptions }\end{array}$ & $\begin{array}{l}\text { How will the program establish guidelines and norms for behavior, and will } \\
\text { those be co-created with young people? How will the program recognize and } \\
\text { reward positive behavior, contributions, and the value of young people? }\end{array}$ \\
\hline & Safe space & $\begin{array}{l}\text { How will the program develop supportive environments where all young } \\
\text { people can feel comfortable? How will the program address the needs of } \\
\text { young people affected by trauma? What policies and practices will be in } \\
\text { place for child and youth protection? How will physical spaces used by the } \\
\text { program be made free of hazards and accessible for young people of various } \\
\text { abilities? How will young people of diverse backgrounds and with varied life } \\
\text { experiences be made to feel safe and supported, regardless of their } \\
\text { differences? }\end{array}$ \\
\hline & $\begin{array}{l}\text { Access to age- } \\
\text { appropriate and } \\
\text { youth-friendly } \\
\text { services; integration } \\
\text { among services }\end{array}$ & $\begin{array}{l}\text { How will the program engage families of participants to increase support for } \\
\text { young people at home, empower parents, and improve family well-being? } \\
\text { How will the program link young people to other community resources and } \\
\text { services? How will the program incorporate wrap-around services? }\end{array}$ \\
\hline
\end{tabular}


While there has been limited evaluation of PYD programs, available evidence suggests that intentionally incorporating PYD principles into programs is more likely to advance meaningful outcomes for the young people they are trying to serve (Lerner et al., 2016). In IYF's experience, asking (and answering) these PYD-aligned questions begins the process of intentionally using the lens of PYD to inform organizational culture and, thereby, overall strategy, approach, and program implementation.

\section{Insights from IYF: Integrating PYD Principles in International Youth Development Programming}

Effective international youth development programs go beyond single-issue interventions-they leverage the entire organization and project life cycle to advance positive youth outcomes. IYF's international implementation experience demonstrates that the integration and application of PYD approaches within organizational and program structures, and leveraging systems-based approaches, leads to greater traction than if they had not been applied. Using project examples across different geographies, sectors, and program goals, the article presents six insights for integrating PYD into programs (Figure 1).

Figure 1. Six Insights for Leveraging PYD Successfully to Advance Youth Outcomes

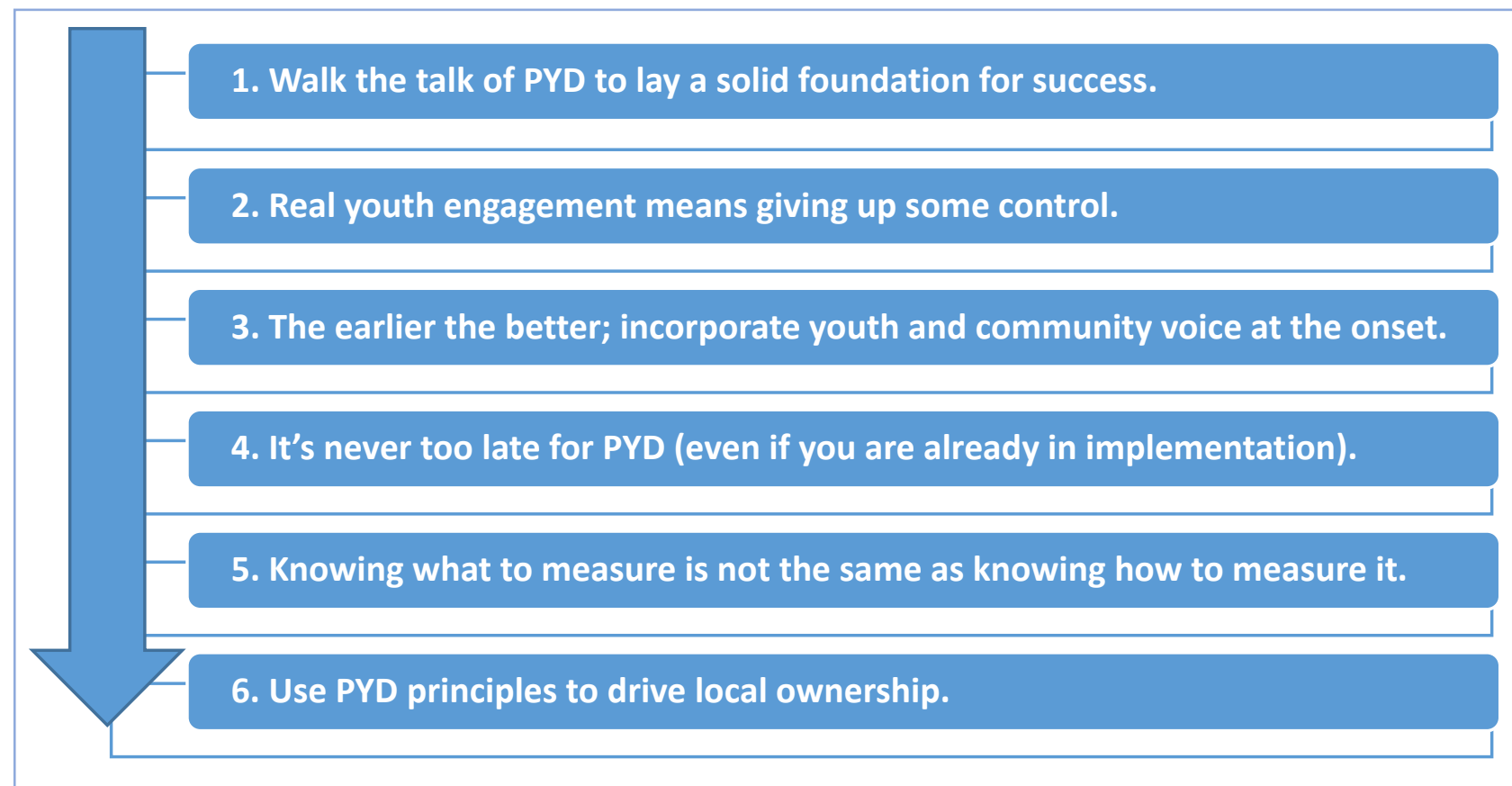




\section{Insight 1. Walk the Talk of PYD to Lay a Solid Foundation for Success}

The foundation for successful and lasting youth development is formed when an organization's institutional practices and values-from explicit policies to implicit ethos-embody the principles of PYD. Organizations such as Educate!, Forum for Youth Investment, $\underline{4-H}$, and IYF, among others, demonstrate this PYD ethos.

\section{Example: The Zangar Program}

In Kazakhstan, the Zangar program embodied this youth-centric character: Zangar (implemented by IYF for Chevron) prepared young people for work in Kazakhstan's growing tech and energy sectors by creating a system of learning and professional skill-building through expanded programs for life skills and the introduction of STEM (science, technology, engineering, math) courses with applied learning. These activities built the assets and agency of young people while strengthening the enabling environment for soft and technical skills.

When Zangar started in 2015, PYD was not a well-known concept in West Kazakhstan. While single-issue prevention programs such as suicide prevention and reproductive health have a long implementation history, Zangar is among the very few PYD programs in the area. Considering the weak enabling environment for PYD, the project team recognized the need for the program to be the "beating heart" of PYD in Kazakhstan. According to Program Director Assem Satmukhambetova: ${ }^{3}$

We wanted our programs to be shaped by the positive way we work, and by IYF's values, not the other way around. Kazakhstan's national education system focuses on gifted students, offering better resources for them while creating access barriers and doing little at the system level to support underperforming students. The five I's: inclusion, impact, innovation, inspiration, and integrity defined how we worked. Consequently, from the very beginning, we decided that positive youth development began with us.

Through this lens, Zangar intentionally built and staffed a program with young professionals, partnered with youth-led organizations, actively incorporated youth input, and set the standard for the community. The program team revised hiring prerequisites-like the type of degree earned or the number of years in the field-to ensure talented young staff were able to get in the door. Walking the talk, IYF was the first job for one-third of the program staff. One project manager explained, "We did not want to recruit just managers, we wanted role models."

\footnotetext{
${ }^{3}$ Assem Satmukhambetova embodied the youth-centric ethos of Zangar, assuming directorship of the program at 28 years of age.
} 


\section{Integrating Positive Youth Development}

Furthermore, Zangar intentionally partnered with organizations that were youth-led and youthstaffed (at least 50\% under 25) and recruited fresh university graduates to manage the Fab Lab Atyrau. These young leaders and peers offered something not reflected by education level and resume length-meaningful experience, trust, empathy, and the ability to relate to young participants. In this way, the young staff set the tone for the organization and set the program up for success.

Basing recruitment and hiring on PYD values was a key element in ensuring PYD was integral to all activities. To set their young professionals up for success, orientation sessions were enhanced with stronger project management training and more comprehensive supervision and mentorship support. This required an initial investment of effort and time that was greater than if IYF had hired a team with more professional experience; however, recruiting, supporting, and investing in recent TVET college and university graduates and young specialists yielded strong connections to youth and their communities. The local ecosystem of actors regarded Zangar as an integral and valued thought-partner, even receiving praise by the former Atyrau regional akim (head of the local executive government).

Having a young team with lived experiences similar to program participants helped build trust and created opportunities for peer-to-peer learning and mentorship throughout the program. Young program participants had a built-in safe space and trusted adults with whom to work. This created space to expand their hopes and dreams for the future-something young people did not always get through Kazakhstan's formal education system. "Fab Lab Atyrau became the main reason why I wanted to stay in Atyrau. Any idea you have can become real here," explained 15-year-old participant and inventor Zhanibek Zheksembay.

\section{Insight 2. Real Youth Engagement Means Giving Up Some Control}

Giving up control is difficult for funding agencies who are used to designing programs and expecting results aligned with their priorities. However, giving up control is necessary if their investments are going to address the actual needs of youth.

Despite the widely accepted view that young people need to be engaged, their perspectives are frequently not considered in the early identification of problems by funding agencies. In other words, youth voices are frequently absent from critical first steps: problem analysis and solution identification. Impediments to greater youth decision making include both systemic barriers and resistance to change. Consulting youth is 'process heavy' which also means it can require a larger budget, greater capacity from staff and potentially longer timelines to execute. Not 


\section{Integrating Positive Youth Development}

surprisingly, one of the most common suggestions heard from young people during program implementation is that they wish they had been consulted by the funder, as the program designs undertaken on their behalf often align more with adult interests than real youth needs.

\section{Example: The Kiongozi Fellowship}

To ensure youth perspectives informed problem identification, Youth Lead Tanzania brought youth voice, choice, and contributions into Irish Aid's program development process through the Kiongozi Fellowship - a youth-led research and co-design model that informed the development of Irish Aid's youth strategy. The project recruited nine young leaders from across Tanzania to become Fellows and ultimately recommend promising youth livelihood and youth engagement models for Irish Aid.

Actively informing Irish Aid's problem analysis and solution identification required a process that simultaneously incorporated youth voices, as well as built youth assets to ensure their contributions had an impact. The work was process-heavy to ensure the desired outcome of youth-driven programmatic solutions.

Kiongozi Fellows started by self-assessing their skills using a baseline survey. Survey results informed a tailored training plan that leveraged their existing skills and experiences for peer-topeer learning-not just adult-led training. Once the fellows were trained and support plans were established, they each began developing a livelihoods-focused case study based on their research findings that included youth-relevant strategy recommendations for Irish Aid. As part of this research process, fellows conducted focus group discussions and secondary research, informing the field research in which young people were trained as enumerators. In addition, they consulted their peers in the pre-testing process and improved the usability and clarity of the instruments.

Fellows led discussions and workshops with Embassy of Ireland staff to share findings. They used post-discussion evaluations to inform a co-design workshop agenda, providing critical feedback and approval to the design process. Fellows led both the agenda planning and execution of a youth dialogue event during which they acted as facilitators and speakers to engage a multi-generational and multi-stakeholder audience in the process. Throughout, it was important to appropriately value and recognize the fellows for their time and expertise, including providing them an honorarium, publishing their case studies, and promoting their stories and bios broadly within the youth development ecosystem. 


\section{Integrating Positive Youth Development}

Through investing in a youth-centric process, Irish Aid acquired a solid theoretical underpinning for their youth development investments, acquired a set of potential program interventions that were relevant for Tanzanian youth, increased legitimacy with local stakeholders, and had the input of trained, invested, and willing young people in the Kiongozi Fellows.

\section{Insight 3. The Earlier, the Better: Incorporate Youth and Community Voice at the Onset}

Embracing the concept of youth engagement has become standard practice for organizations working in the youth development sector. However, shifting that engagement from tokenism to full partnership remains elusive. To incorporate meaningful youth engagement into programming, and learn and adapt from youth input, organizations must partner with young people from the earliest phases of program design, building in activities and processes to ensure continued collaboration throughout the duration of the intervention.

\section{Example: Our Future, Our Voices}

IYF's Our Future, Our Voices global youth summit engaged young people globally as thought partners from the outset. Through a purposeful, six-month, pre-summit slew of brainstorming and planning sessions, IYF ensured that young people from around the world had the opportunity, access, and means to be active leaders, contributors, and partners in the summit's design and delivery. "Young people deserve a real voice," says Anoka Abeyrathne, Youth Advisory Committee (YAC) member from Sri Lanka. "What's better than a summit organized in consultation with real young doers from across the world?"

Our Future, Our Voices was a week-long global virtual summit designed and delivered by, for, and with young people. Youth from 94 countries joined the charge for change as decision makers, session leaders, and participants. With an agenda built around the Sustainable Development Goals, speakers from 30 countries led sessions on creating a more just, equitable, and sustainable future, engaging other young leaders, aspiring change makers, and stakeholders from the corporate, government, and nonprofit sectors.

To ensure the summit was meaningfully youth-led, the Our Future, Our Voices team followed a four-step process to maximize youth leadership: 


\section{Integrating Positive Youth Development}

\section{Understand and remove the barriers-young people can't lead if they can't} participate.

Truly inclusive leadership requires that program managers understand and mitigate the barriers to participation faced by young people-youth can't lead if they can't participate. Oftentimes events built for young people are held in high-cost locations in North America and Europe, far from many of the young people they are supposed to serve. By deciding on a virtual event, the Our Future, Our Voices team actively worked to avoid a situation where only the most privileged young people were able to participate and lead. Financial, familial, employment, visa requirements, disabilities, and other resource constraints can make it difficult for young people, especially those from marginalized communities, to travel to in-person events. A virtual event eliminates many of the logistical barriers young people face. While many 2020 events pivoted to virtual spaces, Our Future, Our Voices, was designed to be a virtual summit from the beginning. From closed-captioning to accessibility compliance to ASL interpretation during the live sessions, the result was an inclusive, truly global summit, with youth participants from $90+$ countries, including strong representation from the global south.

\section{Youth must be a co-equal part of the decision-making process.}

The Our Future, Our Voices team established a Youth Advisory Committee (YAC) with seven members all under the age of 30, representing six different countries. The YAC was not just a sounding board, they had real decision-making authority that fueled event adjustments that would otherwise not have been considered, but ultimately enhanced the experience for participants. Event organizers worked hand-in-hand with the YAC, obtaining their insights around key design questions that ultimately informed the look, feel, and content of the summit. For example, the summit organizers developed an initial concept for the event, including an initial title and tagline. When the team brought it to the YAC, the YAC pushed back and argued that it did not speak to the youth-centric nature and ethos of the event. While the pivot meant delays in the project timeline, the event organizers remained committed to authentic joint learning and decision making with the YAC. The team ultimately adjusted the concept and name through an ideation and consultation process that reflected the YAC feedback. The YAC remained hands-on throughout all phases of the project-from naming and visual identity, through session facilitation and planning, networking, platform design, and promotion. 


\section{Integrating Positive Youth Development}

\section{Meaningful youth engagement requires resources.}

The most difficult decisions to share are often those that have budgetary implications. For example, summit organizers were initially looking at event platform options that offered limited interactivity-the platform first selected was cost-effective and seemed adequate. The YAC emphasized the importance of peer-to-peer interaction and cautioned that for most young people, the event would not be worth attending without an opportunity to connect and exchange ideas with other young people from around the globe. The project team incorporated the input from the YAC and adjusted the overall project budget for a more interactive, more expensive, platform. The interactivity offered during the summit was a differentiating factor from other virtual events. Moreover, the event organizers remained true to the youth-centric ethos, resulting in an online space where young people were actually leading the conversations. As an additional cost, the YAC members were compensated for their time. Recognizing and valuing young people's time and expertise is critical. It may not always be possible to offer financial compensation, but there are other ways to value young people's contributions such as through mentorship, professional development, school credit, reference letters, etc.

\section{Investing in capacity building is critical.}

When young people are set up for success, everyone wins. The Our Future, Our Voices planning team developed a series of skill-building workshops and tools to support youth session anchors and presenters in leading roles. The process of developing the event sessions started with an open call for youth applications that brought in hundreds of proposals. Once selected, young people were invited to participate in customized training sessions, based on their level of participation and role. Additionally, one-on-one mentorship and coaching sessions were offered, and the young presenters were given access to an online resource library containing additional materials to help them prepare for their sessions. The team invested a significant amount of staff time building the capacity of the youth speakers, and it paid off.

Through this early, purposeful, and continual engagement with youth, the Our Future, Our Voices team was able to ensure a diverse group of young people were equipped to step up and take charge of developing, adapting and leading the summit framing and the majority of summit sessions. True engagement rises above tokenism, it involves learning and trust; it demonstrates that when diverse perspectives are sought, and engaged with, solutions are all the richer for it and in this case led to an event that was ultimately more impactful than it would have been otherwise. 


\section{Insight 4. It's Never Too Late for PYD (Even If You Are Already in Implementation)}

Ideally, PYD integration starts at the beginning, yet there is also value in retrofitting ongoing projects with PYD practices that don't already have them. Youth Speak was an initiative that focused on integrating PYD principles into a vocational training project struggling to recruit and retain students in Tanzania. The vocational program had not previously considered PYD and, as a result, was not achieving its target outcomes.

Through the program's learning and adaptation process, Youth Speak identified that there was not a mechanism to gather and incorporate young people's input into the vocational training services that were being offered by partner institutions. Nor were there channels to share youth experiences with the wider public and youth not in vocational training programs. As a result, the training programs were not always accessible to young people or reflective of student's interests and aspirations, which negatively impacted program retention rates. Moreover, the availability of these training programs was not widely known to prospective students in the community, which affected recruitment numbers.

To help solve these problems, Youth Speak created feedback loops between young people and Tanzania's Vocational Education and Training Authority (VETA) by developing internal- and external-facing platforms for young people to amplify their concerns and suggest solutions. These were designed to inform both school administrators and prospective students. Internally this consisted of the creation of a platform to engage young people in the design, planning and implementation of vocational programs. Externally, multiple engagement streams were tied together by creating an interactive website and youth-produced TV show.

Young people were trained in both documentarian storytelling and participatory research practices to equip them with the skills to conduct research and analyze and capture the results. Through video diaries and youth-led research Youth Speak centered on young people's experiences and perspectives as the key to solving the recruitment and retention challenges. The project team also recognized the importance of leveraging multiple engagement streams to reach the widest swath of young people.

To this aim, Youth Speak developed an interactive website and youth-produced TV show that highlighted the real experiences of young people in technical and vocational training programs and careers. On the Kijana Ongea website, young people contributed and connected with relevant social media channels, asked questions and received support from peers, and were 


\section{Integrating Positive Youth Development}

referred to other reliable information sources. The TV show had the widest reach, with 568,000 viewers of the youth-produced six-episode series according to the channel that broadcasted them, East Africa Television (EATV). The TV episodes included students from partner institutions in Dodoma, Dar es Salaam, and Mtwara that featured 117 program participants across three regions.

Retrofitting PYD in a project is difficult, but possible. By leveraging multiple platforms where young people engage (TV and the Web), Youth Speak was able to effectively retrofit the project to mobilize and connect young people within the training programs to those that had otherwise been excluded or unaware. To ensure youth voice continues to inform VETA decision making after the end of the program, Youth Speak worked with the VETA's public relations department and center-level student associations to adopt and sustain the internal platforms as part of their existing mandates. This platform for youth input into VETA training decisions has been adopted by VETA and continues to this day, ensuring youth voice is front and center.

\section{Insight 5. Knowing What to Measure is Not the Same as Knowing How to Measure It}

The PYD domains of assets, agency, contribution, and enabling environment provide a useful framework to guide understanding of what to measure and evaluate in youth development programs. However, while this framework provides guidance for what to measure, programs still have to figure out how to measure different aspects of PYD within the specific program contexts.

Returning to the Kiongozi Fellowship, where an integral part of the program was a focus on youth-driven learning and measurement, IYF learned that to effectively incorporate PYD into measurement one cannot separate what one is measuring from how one is measuring it. The program addressed this fact by integrating two foundational pillars when undertaking PYDdriven measurement: first, measuring and evaluating youth engagement, and second, engaging youth in the process of measurement and adaptation.

Through the process of implementing youth-led measurement, evaluation, and learning activities the Kiongozi Fellowship program surfaced a number of critical actions that needed to take place within each of the two integrated foundational pillars. Table 2 shows those actions in a step-wise fashion along with key takeaways for implementation of each. 
Table 2. Critical Actions to Integrate PYD Into Measurement, Evaluation, and Learning.

\section{Measuring and evaluating youth engagement}

\begin{tabular}{|c|c|}
\hline $\begin{array}{l}\text { 1. Determine measur } \\
\text { priorities }\end{array}$ & $\begin{array}{l}\text { Measuring all four domains has value and is recommended. Assets \& agency are } \\
\text { often the easiest to measure, and they are the bread and butter of a lot of youth } \\
\text { programs. Youth and program level outcomes were the easiest to confirm, with } \\
\text { enabling environment level outcomes fell outside measurement resources. }\end{array}$ \\
\hline $\begin{array}{l}\text { 2. Assess perceptions of youth } \\
\text { engagement and the quality of } \\
\text { youth/adult partnerships }\end{array}$ & $\begin{array}{l}\text { Questions in the fellows' baseline survey targeted their perceptions of their } \\
\text { engagement in the community and the quality of their relationships with adults. As } \\
\text { with many things, practitioners are interested to measure pre- and post- } \\
\text { intervention, these questions were prone to some of the typical issues, namely } \\
\text { social desirability bias and the ceiling effect. }\end{array}$ \\
\hline $\begin{array}{l}\text { 3. Utilize tools to have } \\
\text { participants evaluate project } \\
\text { design and impact }\end{array}$ & $\begin{array}{l}\text { YPAT's youth feedback form gave program participants the opportunity to rate } \\
\text { their engagement in the development intervention, while a Hart's Ladder (Hart, } \\
\text { 1992) mapping exercise provided the structure for youth-led evaluation of } \\
\text { activities. These tools contributed to both measurement and awareness raising, as } \\
\text { the process of measuring and rating activities raised expectations among fellows to } \\
\text { progress from tokenism to shared decision making. }\end{array}$ \\
\hline $\begin{array}{l}\text { 4. Understand that different } \\
\text { stakeholders value different } \\
\text { things from youth engagement }\end{array}$ & $\begin{array}{l}\text { Follow-up events with participants included evaluations that were analyzed by type } \\
\text { of stakeholder. Differing perspectives came up related to the benefit of the activity. } \\
\text { Adults appreciated the opportunity to listen and learn from young people directly. } \\
\text { Youth liked discussing their goals and ambitions with peers and supportive adults. } \\
\text { Donor and government representatives enjoyed the research and data } \\
\text { presentations. }\end{array}$ \\
\hline
\end{tabular}

1. Assess skills perceptions at baseline so training and other activities are for youthexpressed needs and build on their strengths

2. Engage participants in routine monitoring to adaptively manage activities and supports
Fellows self-assessed their skills in the three domains of skills necessary to successfully complete the fellowship. There was also an open-response question that prompted them to share skills they were very confident in and would not mind sharing with their peers. The analysis of these results informed our initial training plan and content-development efforts.

Post-workshop evaluations gave fellows consistent opportunity to identify what was going well, what could go better, and what support they needed from IYF to complete their assignments or participate fully. 


\section{Integrating Positive Youth Development}

One of the key aspects of youth-integrated PYD measurement to remember is that as young people are engaged in the process learn more, they will expect more, shifting their perceptions of how well they have been treated. It is not uncommon for young people to have more negative views of how their contributions are received after the baseline measurement than before as the subsequent PYD training opens their eyes to meaningful youth engagement. Consequently, you will need to establish a prior understanding of PYD concepts before any baseline measurement or measuring drives changes in perception.

\section{Insight 6. Use PYD Principles to Drive Local Ownership}

While targeted skills training is a critical component for strengthening the youth-led development sector, it is equally vital to build a complementary local enabling environment of allies, advocates, and investors to support the scaling and sustainability of youth-led ventures. Some of the greatest challenges for young social entrepreneurs is not building their skills but mobilizing resources and political will from the "big fish" in the system.

In Jordan, the BADIR program launched by IYF and Starbucks equipped young Jordanian leaders with the knowledge and skills needed to strengthen and scale their social enterprises. Early in the program's life cycle, BADIR recognized that it is the enabling environment, not just skills, that both presents the greatest challenges and contains the greatest resources available for young social entrepreneurs. To address this, BADIR cultivated key partnerships including the government, media, corporate and non-profit sectors to join a "Friends of BADIR" network.

BADIR offered private sector partners a three-tiered engagement approach that matched contributions with benefits. BADIR in return positioned the "Friends" as youth-friendly and gave them visibility among key market segments. Amplifying this process was finding and engaging the "big fish"—or the right high-profile champions, influencers, and key opinion leaders—to be engaged and provide market leadership. In the case of BADIR, key stakeholders were invited to be judges for the social investment fund. As a result, these big fish elevated the project in their circles, creating additional visibility and endorsement to the program, and built the initial connections between the emerging social enterprises being supported and the market leaders these social enterprises will need to grow and thrive.

The Friends of BADIR played a critical role in nurturing, growing, and scaling the impact of the youth-led sector in Jordan. They came from a variety of industries including Al Ghad Newspaper, Microsoft, and the British Council, among dozens of others. Through these partnerships, BADIR and its Friends amplified the power and impact of the program by 


\section{Integrating Positive Youth Development}

incentivizing market actors to take the lead in activities including employment outreach and recruitment communications, shared employee engagement, leadership and mentorship in the selection of social entrepreneurs, financial investment in the program and participants, fully engage in BADIR's competitive social investment fund, and a diverse contribution of shared learning opportunities and resources.

The successful engagement of the private sector and other organizations in the local ecosystem didn't happen by accident. BADIR used a very deliberate process of selection that leveraged the principles of PYD to bring in the right partners from the enabling environment. To ensure close alignment with the youth development goals of BADIR, all Friends of BADIR had to consistently provide positive contributions and benefits while being socially minded and respected as an ethical and youth-friendly organization, and also provide targeted support to youth social entrepreneurs to help advance their goals and objectives.

\section{Conclusion - Integrating PYD Into Programs is the Starting Point, Not the Finish Line}

Using examples across different geographies, sectors, and program goals, the article presented six insights for integrating PYD into youth development programs. Based on this experience, effective programs go beyond single-issue interventions-they leverage the entire organization and life cycle of the project to advance positive youth outcomes.

However, integrating PYD is not a one-size-fits-all solution. Context matters, the local political economy matters, organizational ethos matters, and most importantly engaging youth and valuing their contributions matters. Youth must be engaged as early and often as possible throughout the project life cycle. It is young people who possess the greatest understanding of their own needs and the creativity and energy to see old problems in new ways.

PYD approaches take time, money, and a significant coordinated effort among program staff, youth, their communities, and local stakeholders to implement. It is not easy, while at the same time it is not yet systematically part of how most international development practitioners design and implement programs. Moreover, investments in PYD don't always align with funders that look at 'cost per beneficiary' metrics and determine success based on total numbers of youth served. To truly value youth contribution, practitioners and funders must find new ways to measure and value PYD investments. 
While the focus of this paper is on integrating PYD program models into international youth development programs, these youth programs are a limited piece of the overall international development ecosystem. Practitioners and funders must explicitly integrate PYD principles into their funding streams across all sectors. Doing so would incentivize and hold accountable development practitioners to better integrate PYD principles and outcomes, and those programs would better align with young people's needs and realities. Stated plainly, PYD would become a "must have," not a "nice to have." Explicitly integrating PYD into funder requirements will also drive organizations who may not be youth-serving organizations or have the same values to integrate PYD principles in their own organizational ethos and walk the talk in their own communities.

\section{Acknowledgements}

The authors wish to thank Pia Saunders Campbell, Matthew Hobson and Jessica Elisberg for their contribution to this work.

\section{References}

Alvarado, G., Skinner, M., Plaut, D., Moss, C., Kapungu, C., \& Reavley, N. (2017). A systematic review of positive youth development programs in low-and middle-income countries. YouthPower Learning, Making Cents International. https://www.youthpower.org/resources/systematic-review-positiveyouth-development-programs-low-and-middle-income-countries

Burkhard, B. M., Robinson, K. M., Murray, E. D., \& Lerner, R. M. (2020). Positive youth development: Theory and perspective. In S. Hupp and J. Jewell (Eds.), The encyclopedia of child and adolescent development. https://doi.org/10.1002/9781119171492.wecad310

Hart, R., 1992. Children's participation. UNICEF International Child Development Centre.

Lee, T. Y., Cheung, C. K., \& Kwong, W. M. (2012). Resilience as a positive youth development construct: A conceptual review. The Scientific World Journal, Article ID 390450, 1-9. https://doi.org/10.1100/2012/390450

Lerner, R. M., Lerner J. V., \& Colleagues. (2016). The positive development of youth: Comprehensive findings from the 4-H study of positive youth development. Institute for Applied Research in Youth Development, Tufts University. https://4-h.org/wp-content/uploads/2016/02/4-H-Study-ofPositive-Youth-Development-Full-Report.pdf

Sanders, J., Munford, R., Thimasarn-Anwar, T., Liebenberg, L., \& Ungar, M. (2015). The role of positive youth development practices in building resilience and enhancing wellbeing for at-risk youth. Child Abuse \& Neglect, 42, 40-53. https://doi.org/10.1016/j.chiabu.2015.02.006 
Journal of Youth Development | http://jyd.pitt.edu/ | Vol. 16 Issue 2-3 DOI 10.5195/jyd.2021.1037 Integrating Positive Youth Development

Ward, R. L., Carter, T., \& Siddiq, N. (2019). The role of positive youth development, educational policy, and cultural relevancy in school settings. EJournal of Public Affairs. www.ejournalofpublicaffairs.org/the-role-of-positive-youth-development-educational-policy-andcultural-relevancy-in-school-settings/

YouthPower2. (n.d.). Positive youth development (PYD) framework. Retrieved September 10, 2020, from https://www.youthpower.org/positive-youth-development-pyd-framework 